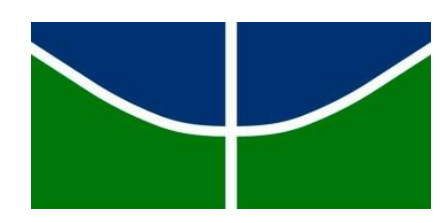

UNIVERSIDADE DE BRASÍLIA INSTITUTO DE CIÊNCIAS HUMANAS DEPARTAMENTO DE HISTÓRIA

HISTORICIZANDO REPRESENTAÇÕES DE GÊNERO E RAÇA NO ENSINO DE HISTÓRIA: RESULTADOS DE UMA PESQUISAAÇÃO

Thaís Lima de Sousa

BRASÍLIA

2017 
Thaís Lima de Sousa

Historicizando representações de gênero e raça no ensino de história:

Resultados de uma pesquisa-ação

Artigo apresentado ao Departamento de História do Instituto de Ciências Humanas da Universidade de Brasília como requisito parcial para a obtenção

do grau de licenciado em História.

Orientadora: Profa. Dra. Susane Rodrigues de Oliveira

Brasília 


\title{
Historicizando representações de gênero e raça no ensino de história: Resultados de uma pesquisa-ação
}

\section{Resumo}

O artigo apresenta os resultados de uma pesquisa-ação realizada em uma turma de $1^{\circ}$ ano do Ensino Médio em uma escola pública do Distrito Federal, durante o primeiro semestre de 2016, com o objetivo de planejar e aplicar uma oficina de ensino de história afro-brasileira que colaborasse no enfrentamento de problemas como o racismo e o sexismo ainda vigentes em nossa sociedade. Esta oficina foi dedicada à problematização e historicização das representações estereotipadas de homens negros e mulheres negras presentes no cotidiano brasileiro. Os resultados revelam os efeitos positivos dessa prática pedagógica no sentido de promoção da conscientização e aprendizagem dos estudantes sobre os aspectos históricos constitutivos do racismo e sexismo em nossa sociedade, de modo a questionar e romper com a naturalização e perpetuação de representações estereotipadas sobre as pessoas negras no tempo presente

Palavras-chave: Representações; Gênero; Raça; Pesquisa-ação; Ensino de História.

\begin{abstract}
This paper aims to present the results of an action research fullfiled in the first year of High School at a public institution in the Federal District, during the first half of 2016, with the objective of planning and implementing an Afro-Brazilian history teaching workshop that would collaborate in coping with problems such as racism and sexism in our society This workshop was dedicated to the problematization and historicization of the stereotyped representations of black men and black women present in Brazilian daily life. The results reveal the positive effects of this pedagogical practice in the sense of promoting students' awareness and learning about the constitutive historical aspects of racism and sexism in our society, in order to question and break with the naturalization and perpetuation of stereotyped representations about black people in the present tense.

Key-words: Representation; Gender; Race; Action Research; History Teaching.
\end{abstract}

\section{Introdução}

Esse artigo apresenta os resultados de uma pesquisa-ação realizada em uma turma de $1^{\circ}$ ano do Ensino Médio em uma escola pública do Distrito Federal, durante o primeiro semestre de 2016, com o objetivo de planejar e aplicar uma oficina de ensino de história afrobrasileira que colaborasse no enfrentamento de problemas como o racismo e o sexismo ainda vigentes em nossa sociedade. Esta oficina foi dedicada à problematização e historicização das representações estereotipadas de homens negros e mulheres negras presentes no cotidiano brasileiro. 
Para isso apresentamos em sala de aula imagens de pessoas negras famosas que foram e são referências mundiais, com o intuito de romper com os estereótipos presentes no imaginário coletivo e evidenciar uma "História do possível" (NAVARRO-SWAIN, 2014), ou seja, daquilo que foi ocultado e invisibilizado pelo racismo e sexismo epistêmico presente na História escolar.

Em se tratando de representação de gênero e raça no contexto escolar, a pedagoga Nilma Lino Gomes afirma que

\begin{abstract}
A escola não é um campo neutro onde, após entrarmos, os conflitos sociais e raciais permanecem do lado de fora. A escola é um espaço sócio-cultural onde convivem os conflitos e as contradições. O racismo, a discriminação racial e de gênero, que fazem parte da cultura e da estrutura da sociedade brasileira, estão presentes nas relações entre educadores(as) e educandos(as) (1996, p 72.)
\end{abstract}

A afirmação de Gomes aponta para uma realidade vivida entre docentes e discentes diariamente e promove uma reflexão sobre como têm sido ensinados os conteúdos que abordam questões sensíveis às formas de representação de gênero e raça em suas intersecções. Não é possível, portanto, que pensemos no ambiente escolar como alheio às realidades socioculturais. A escola é responsável por um ensino que permita aos estudantes a compreensão de aspectos que estruturam e dominam as relações étnico-raciais e de gênero em nossa sociedade. Neste viés, a Lei 10.639/03, alterada posteriormente pelo artigo 26-A da Lei 11.645/08, torna obrigatório o ensino de História da cultura afro-brasileira, africana e indígena em todas as escolas, públicas e privadas, do ensino fundamental ao médio com o propósito de que o conteúdo programático a que se refere este artigo incluirá diversos aspectos da história e da cultura que caracterizam a formação da população brasileira, a partir desses dois grupos étnicos, tais como o estudo da história da África e dos africanos, a luta dos negros e dos povos indígenas no Brasil, a cultura negra e indígena brasileira e o negro e o índio na formação da sociedade nacional, resgatando as suas contribuições nas áreas social, econômica e política, pertinentes à história do Brasil, bem como que os conteúdos referentes à história e cultura afro-brasileira e dos povos indígenas brasileiros sejam ministrados no âmbito de todo o currículo escolar, em especial nas áreas de educação artística, literatura e história brasileira.

Pensando nisso, a pesquisa-ação que buscamos desenvolver teve por objetivo não só colaborar na formação inicial de professores para a implementação destas Leis, mas também contribuir com a escola no desenvolvimento e promoção de práticas pedagógicas antirracistas 
e antissexistas, por meio da historicização de representações estereotipadas de gênero e raça que estão fortemente cristalizadas e arraigadas no imaginário ${ }^{1}$ dominante em nossa sociedade.

Com base nas concepções de Paviani, elaboramos também essa oficina pedagógica com duas finalidades:

(a) articulação de conceitos, pressupostos e noções com ações concretas, vivenciadas pelo participante ou aprendiz; e b) vivência e execução de tarefas em equipe, isto é, apropriação ou construção coletiva de saberes. $\mathrm{O}$ professor ou coordenador da oficina não ensina o que sabe, mas vai oportunizar o que os participantes necessitam saber, sendo, portanto, uma abordagem centrada no aprendiz e na aprendizagem e não no professor. Desse modo, a construção de saberes e as ações relacionadas decorrem, principalmente, do conhecimento prévio, das habilidades, dos interesses, das necessidades, dos valores e julgamentos dos participantes 2009, p. 77-88).

Este artigo está organizado em três partes, na primeira apresentamos uma discussão teórica sobre representações e estereótipos, atentando para as intersecções de gênero e raça nas representações de mulheres negras. Na segunda parte, tratamos dos objetivos, características e etapas da pesquisa-ação. Já na terceira e última parte descrevemos a ação pedagógica em sala de aula, bem como os seus resultados na aprendizagem dos alunos.

\section{Representações e estereótipos}

De acordo com Stuart Hall (1997), as representações são parte essencial do processo pelo qual os significados são produzidos e compartilhados entre os membros de uma determinada cultura. As representações produzem sentidos para o mundo. Elas estão "no modo como se referimos às coisas, nas histórias que narramos a seu respeito, nas imagens que dela criamos, nas emoções que associamos a elas, nas maneiras como as classificamos e conceituamos, nos valores que nelas embutimos” (HALL, 2016, p. 21). Na concepção do autor, a cultura se dá como um conjunto de significados, cujos sentidos são atribuídos por meio da linguagem. Os significados em uma cultura só podem ser partilhados pelo acesso comum à linguagem, que funciona como um sistema de representação. Desse modo, Hall defende que é por meio da linguagem que os sentidos são produzidos.

A riqueza fenomênica e cultural das representações se configura em elementos diversos: cognitivos, ideológicos, opiniões, imagens, valores, crenças, atitudes e afins, que

\footnotetext{
${ }^{1}$ Para Backzo (1985), o imaginário é um lugar estratégico e responsável pela apropriação de símbolos e sentidos que possibilitam a manutenção de poder e controle social.
} 
esboçam a realidade, ainda que não seja, em sua plenitude, verossímil. Há, portanto, uma união de conceitos psicológicos, culturais e sociais que emergem em uma riqueza e pluralidade de representações que se dão aquém de procedimentos empíricos, mas também por meio de construções sociais que denotam que todas essas práticas mentais têm origem na sociedade, sendo, assim, categoriais sociais do pensamento que comportam sentidos produzidos em determinados tempos e espaços. Ainda de acordo com Hall, "o sentido é constantemente elaborado e compartilhado em cada interação social e pessoal" (2016, p. 22). Desse modo, podemos dizer que as representações possuem historicidade, já que estão conectadas com a cultura e a linguagem de determinada época, lugar ou grupo social. Elas são partes constitutivas do mundo, tão fundamentais "quanto a base econômica ou material para a configuração de sujeitos sociais e acontecimentos" (HALL, 2016, p. 26).

As representações estão na base do senso comum, nos processos de comunicação e interação cotidianos, quando então emulam os quadros de referência para a ação (JODELET, 2001). Sendo sociais, as representações são inevitavelmente históricas (ROUQUETTE, 1994) e, por serem produzidas em distintos contextos, possuem um caráter estruturante ao mesmo tempo em que são, ainda, estruturadoras. Ora, já que as representações possuem sua historicidade, cabe a nós analisar e ensinar sobre os seus processos de construção, modos de funcionamento e efeitos na vida social

Pensando em como se dão as representações raciais, é sabido que as representações de afrodescendentes e africanos que circulam na grande mídia, retratadas no cinema, na literatura e ensinadas nos livros didáticos são, em grande parte, dotadas de estereótipos e preconceitos que se arraigaram no imaginário coletivo e revelam uma conjuntura marcada historicamente pelo racismo, classismo e sexismo (SHOHAT \& STAM, 2006, p. 261).

No tangente à alteridade, sobretudo no que diz respeito a como as representações populares da "diferença" racial são construídas e difundidas, Hall elucida os status, também entendidos como estereótipos, que oferecem a "evidência incontestável" para a naturalização dessa diferença. Há, entre eles, a ideia de uma "preguiça inata" dos negros, de que eles teriam naturalmente nascidos aptos para a servidão ao mesmo tempo em que seriam teimosamente e indispostos a trabalhar, contrariando, assim, sua própria natureza. O estereótipo do "primitivismo", que acentua um conjunto de oposições binárias nas quais apontam para a oposição do branco civilizado versus o negro selvagem é, também, um exemplo de como a construção e difusão desses estereótipos apontam para os negros de modo a inferioriza-los perante os brancos. 
Sobre esses estereótipos e os poderes dos quais estes estereótipos estão imbuídos cultural e socialmente, Hall (2016) explica que, na estereotipagem, há uma conexão entre representação, diferença e poder. Quando pensamos em poder, logo associamos a um poder em termos de restrição ou coerção física, contudo, é necessário que demarquemos a influência do poder simbólico na natureza e implementação de estereótipos. Por meio de práticas representacionais, o poder simbólico está intimamente ligado ao conhecimento ou às práticas chamadas por Foucault de "poder/conhecimento", também denominadas por outros teóricos como "colonialidade do saber"2.

Entretanto, não podemos tratar das representações raciais e historicizar como se deu, ao longo da história, a construção e difusão de estereótipos sobre pessoas negras, sem trazer para o debate a questão de gênero. No que diz respeito às maneiras como mulheres negras são representadas, é necessário apontar a interseccionalidade entre racismo e sexismo. O racismo, assim como o sexismo, são fenômenos dinâmicos que se manifestam distintamente a depender de seus contextos históricos, mas se assemelham, entretanto, por serem dispositivos de poder e pelo caráter de determinação de papéis na sociedade. Quando nos referimos a essas determinações, é no sentido de que a cor e o sexo das pessoas podem ganhar sentidos negativos que de alguma forma podem influir diretamente nos espaços que as pessoas podem ou não ocupar socialmente.

Tanta a raça como o gênero constituem representações sociais que marcam diferenças e desigualdades baseadas em aspectos biológicos como a cor e a genitália. Para Lauretis (1987, p. 208-09), o gênero "como representação" e "auto-representação" é produto de diferentes tecnologias sociais como a ciência, o cinema, a mídia, a escola, a literatura, etc. Já a raça, na perspectiva de Munanga,

Se na cabeça de um geneticista contemporâneo ou de um biólogo molecular a raça não existe, no imaginário e na representação coletivos de diversas populações contemporâneas existem ainda raças fictícias e outras construídas a partir das diferenças fenotípicas como a cor da pele e outros critérios morfológicos. É a partir dessas raças fictícias ou "raças sociais" que se reproduzem e se mantêm os racismos populares. (...) Alguns biólogos anti-racistas chegaram até sugerir que o conceito de raça fosse banido dos dicionários e dos textos científicos. No entanto, o conceito persiste tanto no uso popular como em trabalhos e estudos produzidos na área das ciências sociais. Estes, embora concordem com as conclusões da atual Biologia Humana sobre a inexistência científica da raça e a inoperacionalidade do

\footnotetext{
${ }^{2}$ A colonialidade do saber se relaciona com a epistemologia e suas formas de reprodução de regimes de pensamento, enquanto a colonialidade do ser se refere à experiência vivida de colonização e seus impactos na linguagem e na visão de mundo dos povos colonizados (Maldonado-Torres, 2007).
} 
próprio conceito, eles justificam o uso do conceito como realidade social e política, considerando a raça como uma construção sociológica e uma categoria social de dominação e de exclusão $(2003$, p. 6).

Observar as intersecções entre gênero, classe e raça é importante no entendimento das representações de homens negros e mulheres negras no Brasil. Para Crenshaw, a interseccionalidade sugere que, na verdade, nem sempre lidamos com grupos distintos de pessoas e sim com grupos sobrepostos (CRENSHAW, 2002, p.10). Em síntese, no que diz respeito à interseccionalidade, Silma Bilge nos explica que

\begin{abstract}
A interseccionalidade remete a uma teoria transdisciplinar que visa apreender a complexidade das identidades e das desigualdades sociais por intermédio de um enfoque integrado. Ela refuta o enclausuramento e a hierarquização dos grandes eixos da diferenciação social que são as categorias de sexo/gênero, classe, raça, etnicidade, idade, deficiência e orientação sexual. O enfoque interseccional vai além do simples reconhecimento da multiplicidade dos sistemas de opressão que opera a partir dessas categorias e postula sua interação na produção e na reprodução das desigualdades sociais $(2009$, p. 70$)$.
\end{abstract}

Já no que se refere às representações das mulheres na História, concordamos com Michelle Perrot ao dizer que

\begin{abstract}
O "ofício do historiador" é um ofício de homens que escrevem a história no masculino. Os campos que abordam são os da ação e do poder masculinos mesmo quando anexam novos territórios. Econômica, a história ignora a mulher improdutiva. Social, ela privilegia as classes e negligencia os sexos. Cultural ou "mental", ela fala do Homem em geral, tão assexuado quanto a Humanidade. Célebres - piedozas ou escandalosas -, as mulheres alimentam as crônicas da "pequena” história, meras coadjuvantes da História!" (1992, p.185).
\end{abstract}

Esse quadro marcado pela omissão das mulheres na História é ainda pior quando se trata das mulheres negras na história. Pensadoras feministas negras têm buscado reivindicar a história com o intuito de alterar as concepções no que diz respeito às questões de gênero/raça encaradas como naturais, indicando que estas concepções são construídas social e culturalmente. Para bell hooks (1995, p. 482), devido à atuação conjunta entre racismo e 
sexismo, a iconografia utilizada para representar as mulheres negras imprime no imaginário coletivo a ideia de que elas estão no mundo, principalmente, para servir os outros.

De acordo com os dados do Instituto de Pesquisa Aplicada - IPEA, divulgados em março de 2014 por meio da "Nota Técnica - Estupro no Brasil: uma radiografia segundo os dados da saúde", $51 \%$ das vítimas violência sexual eram mulheres negras. Já o estudo denominado "Mapa da violência 2015 - Homicídio de mulheres no Brasil” constatou o aumento de 54,2\% no número de homicídios sofridos por mulheres negras. Quando deparamo-nos com esses números, enxergamos as violências que as mulheres negras brasileiras são submetidas e que, diretamente, se relacionam com as formas como elas são representadas, já que as representações de gênero e raça corroboram para um quadro marcado pelas desigualdades e violências pautadas por raça, classe e gênero.

\title{
2. Pesquisa-ação: objetivos e procedimentos
}

\begin{abstract}
A pesquisa-ação é um tipo de pesquisa social que é concebida e realizada em estreita associação com uma ação ou com a resolução de um problema coletivo e no qual os pesquisadores e os participantes representativos da situação da realidade a ser investigada estão envolvidos de modo cooperativo e participativo (THIOLLENT,1985, p. 14).
\end{abstract}

A pesquisa-ação visa diminuir a lacuna que existe entre teoria e prática na pesquisa acadêmica. Este método ganhou força a partir da década de 1960. A psicologia foi pioneira na proposta em aliar pesquisa e ação, com o seu precursor Kurt Lewin (ENGEL, 2000). Depois, os cientistas sociais aderiram à prática, visando encarar a responsabilidade de aplicar suas teorias, desenvolvidas por meio da pesquisa e encarar os resultados através da prática.

Caracterizada pela maior aproximação do pesquisador com seu objeto de pesquisa, a pesquisa-ação possibilita grandes análises em várias áreas do conhecimento e possui algumas peculiaridades que precisam ser levadas em consideração para maior eficácia dos resultados. A principal singularidade dessa modalidade de pesquisa é a não representatividade, ou seja, o plano de ação e a conclusão de uma pesquisa-ação, feita em determinada escola, podem não ser aplicáveis ou eficientes em outras instituições. Os resultados obtidos por esse tipo de pesquisa não podem ser generalizados ou representar a solução do mesmo problema em outro contexto. O contexto social e histórico do local tem peso decisivo para o resultado desse tipo de pesquisa. O cientista social Guido Irinel Engel (2000, p. 181-191) explica que esse método possui oito fases de ação: a definição de um problema, a pesquisa preliminar, a identificação 
de uma hipótese, o desenvolvimento de um plano de ação, a coleta de dados para a avaliação dos efeitos da implementação do plano de ação aplicado e sua avaliação.

A pesquisa-ação que resultou na confecção deste trabalho foi fruto de um trabalho realizado no primeiro semestre de 2016 na disciplina de Prática de Ensino de História 1, do departamento de História da Universidade de Brasília. Nesta disciplina desenvolvemos o “Projeto Mbopyau: ensinando histórias do possível" "3". Trata-se de uma iniciativa de estágio docente supervisionado que desenvolve a pesquisa-como-ação no ensino de história, com a finalidade de problematização e transformação sistemática de saberes históricos escolares e práticas educativas. Essa reorientação das práticas educativas se dá a partir da compreensão de seus contextos e condicionantes. Este projeto foi desenvolvido em duas fases: na primeira, fizemos observações do cotidiano escolar e de aulas de história, com a finalidade de reconhecer os desafios, problemas, possibilidades, necessidades e interesses coletivos (de professores e alunos) que envolvem a implementação da lei 11.645/2008 na escola; já na segunda e última fase planejamos e executamos uma ação pedagógica com o apoio do professor/supervisor na escola.

A reflexão, interação e intervenção no espaço escolar possibilitam ao/à futuro/a professor/a pesquisador/a uma inserção profissional crítica, transformadora e criativa. Desse modo, a pesquisa-ação desenvolvida no estágio docente pretende contribuir na formação de futuros/as professores/as de história e na construção e aprimoramento de práticas pedagógicas decoloniais, antirracistas e de respeito à diversidade étnico-racial.

Desenvolvemos esse projeto em grupo, juntamente com os colegas de graduação Daniella Leite e Lucas Querino. Realizada em maio de 2016, a primeira etapa do projeto contou com as 20 horas de observações em uma sala de aula do Centro de Ensino Médio Paulo Freire, localizado no bairro Asa Norte da cidade de Brasília, no Distrito Federal.

Por aliar teoria à prática, a pesquisa-ação nem sempre será terreno fértil para proporcionar o que os pesquisadores sugerem para um plano de ação perfeito. Quando se trata de graduandos promovendo essa metodologia, a dificuldade é ainda maior, já que o tempo é determinado pelo/a professor/a responsável pela turma. A professora que nos permitiu a observação estava com tempo limitado por conta de alguns conteúdos curriculares atrasados, o que impossibilitou a aplicação dos questionários, previstos inicialmente no projeto de estágio, no tempo ideal, visto a enorme quantidade de questões que possuía, sendo assim a

\footnotetext{
${ }^{3}$ Mbopyau quer dizer na língua guarani "relembrar, deixar novo, renovar". Trata-se de um projeto coordenado pela professora doutora Susane Rodrigues de Oliveira no Laboratório de Ensino de História da UnB.
} 
identificação do problema que nos conduziu ao planejamento da oficina pedagógica, foi feita por meio da observação das aulas de história.

Em uma das aulas que observamos, o conteúdo ministrado pela professora dizia respeito à história do Egito Antigo. Com o intuito de trazer aos estudantes outras análises no que se refere às representações dos agentes históricos dessa época, a professora apresentou aos alunos(as) o texto "Um Egito negro incomoda muita gente", escrito pela escritora Charô Nunes e disponível no website Blogueiras Negras. ${ }^{4}$. O texto diz respeito ao embranquecimento nas representações de homens e mulheres negras dessa época, sobretudo veiculado pela indústria cinematográfica. Percebemos que esse conteúdo proporcionou aos estudantes alguns questionamentos e reflexões no que diz respeito às formas como essas pessoas são representadas. A professora, nesta mesma aula, conseguiu sanar muitas das dúvidas que os estudantes tinham, mas acreditamos que levar aos estudantes as questões representacionais com maior riqueza de detalhes, bem como explicar os processos históricos que culminaram, sobretudo, na maneira como têm sido representados(as) os homens e mulheres negros(as) seria interessante e compatível com a proposta do projeto.

Perante a situação descrita e a dificuldade em encontrarmos, nos questionários, algo que pudesse colaborar com a implementação da nossa ação pedagógica, o tema escolhido para a oficina foi a História das imagens de mulheres e homens negros no Brasil, visto que as representações sociais têm peso significativo no que diz respeito à cristalização de conceitos, discursos, práticas e ideologias; tendo como pressuposto a verossimilhança, ou seja, a representação de uma realidade que nem sempre é condizente e pode ser por vezes carregada de estereótipos. Essa oficina teve por intenção ensinar e esclarecer como se deu, historicamente, a construção de imagens de mulheres e homens negros na sociedade brasileira e desnaturalizá-las por meio de uma prática pedagógica decolonial, antirracista e antissexista.

\section{A ação pedagógica em sala de aula e seus resultados}

Em sala de aula, apresentamos aos estudantes uma oficina cujo tema era A História das imagens de mulheres e homens negras/os no Brasil. Nossos objetivos se pautaram, em suma, na investigação das diversas impressões que os alunos possuíam sobre as

\footnotetext{
4 Disponível em: <http://blogueirasnegras.org/2014/08/11/um-egito-negroincomoda-muita-gente/>
} 
representações estereotipadas de homens e mulheres negras que circulam na mídia brasileira; na discussão sobre a relação dessas imagens com os discursos e práticas racistas, sexistas, classistas e colonialistas que foram constituídos através dos tempos; na desnaturalização e descolonização destas imagens no que diz respeito à exposição de seu caráter histórico-social e na revelação de outras imagens históricas que possibilitaram a visualização do protagonismo e pluralidade identitária de mulheres e homens negros através dos tempos e na discussão sobre a força das representações na orientação das práticas, comportamentos, identidades e relações raciais e de gênero no Brasil.

Elencamos temas e questões que poderiam colaborar para atingir os objetivos propostos para essa oficina, são eles: o protagonismo de negros (as) através dos tempos no Brasil; a história das imagens dos(as) negros(as) no Brasil; o racismo e sexismo na mídia brasileira; o colonialismo, a escravidão e o trabalho doméstico no Brasil; a criminalidade e marginalização de homens negros; e os preconceitos, estereótipos e discriminações raciais no Brasil.

O tema do planejamento da ação pedagógica apresentado acima surgiu a partir de uma das observações que fizemos em sala, em que a professora, ao ministrar o conteúdo sobre Egito Antigo, questionou e problematizou as representações de mulheres e homens negros/as nesse período da história, que estão presentes e circulam na mídia, sobretudo na indústria cinematográfica.

Visto que esse foi um assunto que despertou o interesse dos estudantes, consideramos importante tratar da historicidade das representações de pessoas negras na história do Brasil. Além disso, notamos entre os alunos daquela turma um desconhecimento sobre os quilombos e a resistência de negros(as) escravizados(as) ao regime escravocrata brasileiro.

Pensando nisso, resolvemos tratar na ação pedagógica de três representações discriminatórias e estereotipadas dos afrodescendentes no decorrer da história do Brasil, observando e problematizando a posição de subalternidade e subserviência bem como a objetificação e hipersexualização das mulheres negras, além da marginalização e criminalização dos homens negros.

Por meio de um acervo bibliográfico e iconográfico sobre os temas, colhemos algumas imagens capturadas ao longo do tempo que evidenciam essas posições de subalternidade, sexualização e marginalização dos/as negros/as. Preparamos uma apresentação em PowerPoint com intuito maior de historicizar como se deram essas práticas de servidão, racismo, discriminação, sexismo e machismo contra mulheres e homens negros. 
No dia 16 de junho de 2016 colocamos em prática nossa ação pedagógica, com durabilidade de 40 minutos, na turma de $1^{\circ}$ ano do Ensino Médio. A primeira apresentação foi sobre a posição de subalternidade e subserviência das mulheres negras, ilustrada por meio de três fotografias do livro O negro na fotografia brasileira do século XIX (EMARKOFF, 2004). Seguem abaixo as imagens citadas.

\section{Figura 1}

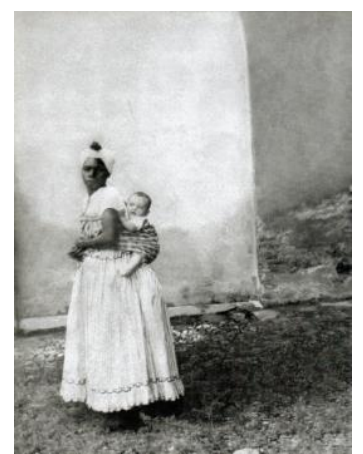

Fontes: Fotógrafo não identificado, Negra com criança branca presa às costas, Bahia, 1870. Acervo Instituto Moreira Sales.

\section{Figura 2}

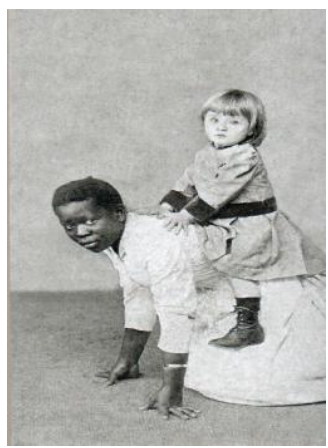

Fontes: J. H. PAPF, Babá brincando com criança em Petrópolis, 1899. Coleção G. Ermakoff.

\section{Figura 3}




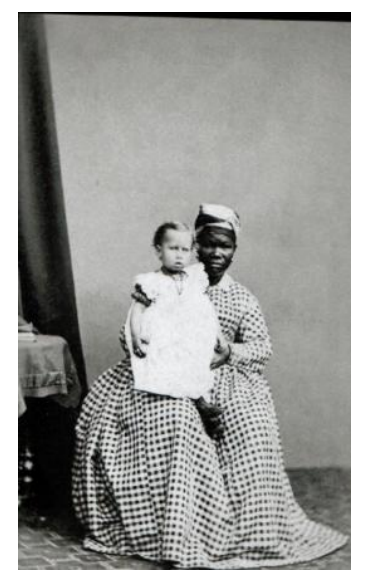

Fonte: The London Stereoscopic and Photographic Company, Negra com criança, Coleção Emanuel Araújo.

Dessas três fotografias, uma foi capturada em 1870 no Estado da Bahia e representa uma mulher negra, escravizada, segurando em suas costas uma criança branca, provavelmente filha de seus senhores. As outras duas imagens, uma capturada em 1899 e outra sem data definida, têm o mesmo teor de representação: mulheres negras, carregando nas costas ou no colo crianças brancas, provavelmente filhas de seus senhores. Após a apresentação dessas imagens, foi lançado o seguinte questionamento aos estudantes: o que vocês enxergam nestas imagens? As reações foram as mais diversas, desde a resposta de que na imagem havia dois seres humanos às reflexões mais aprofundadas sobre como as imagens representavam o racismo. A partir daí, ressaltamos que as fotografias, embora fossem datadas de diferentes momentos (no contexto pré e pós-abolição da escravatura no Brasil), tinham o mesmo caráter representativo de servidão e subalternidade. Nesse sentido, iniciamos um debate a fim de demonstrar a sujeição e subordinação e explanação sobre como o trabalho doméstico ficou, em grande parte, a encargo das mulheres negras e escravizadas no Brasil partindo da análise da história dos trabalhadores no Brasil do pós-abolição, que se iniciou com divisões marcadas e consolidadas na sociedade sendo que, de um lado, estava a sociedade latifundiária exercendo seu poder socioeconômico e, do outro, a massa de homens e mulheres negros(as) recém libertos ou liberto há muito tempo tidos como sem "qualificação" e sem perspectiva concreta de inserção no mundo do trabalho. Essas pessoas ficaram, portanto, a encargo de trabalhos tidos como "subalternos" (PEREIRA, 2011).

Ao começarmos a parte sobre como o corpo das mulheres negras é retratado ao longo do tempo na sociedade brasileira, os alunos prestaram bastante atenção. Iniciamos essa temática mostrando uma fantasia de "nega maluca", muito comum na época do carnaval, e que aparecia em uma foto (veja abaixo) na qual uma pessoa abusava das características, estereotipando e ridicularizando os fenótipos das mulheres negras. 
Figura 4

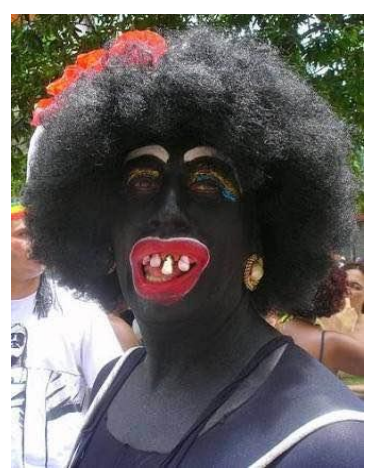

Fonte: Fantasia de Nega Maluca. (Disponível em: http://agenciapatriciagalvao.org.br/mulher-emidia/representacao-social-da-mulher-negra-nos-programas-de-tv-estereotipo-sexualizacao/) ${ }^{5}$

Diante dessa imagem, perguntamos aos estudantes se alguém já havia parado para pensar em como as mulheres negras se sentem ao verem-se retratadas dessa maneira. Os alunos não responderam, mas ficaram reflexivos diante desse questionamento e demos continuidade à apresentação. No slide seguinte falamos de como o corpo das mulheres negras foi representado no Brasil Colônia, para isso mostramos que segue logo abaixo e aproveitamos o gancho para dar enfoque à desumanização e coisificação de mulheres escravizadas, transmitindo a ideia de que esse aspecto legitimava a violência sexual das mulheres escravizadas por parte dos seus senhores, já que as mulheres negras e os homens negros eram vistos como uma propriedade.

\section{Figura 5}

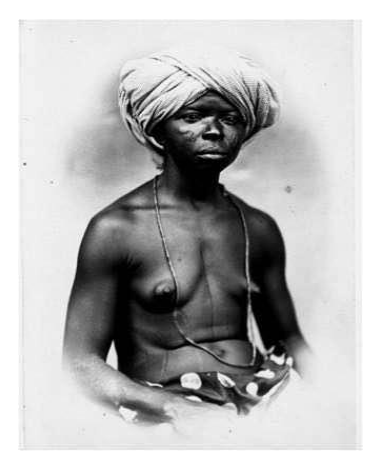

Fonte: Augusto Stahl, Ondo Minah, 1865. The Peabody Museum of Archeaology e Ethnology.

Para problematizar a criminalização e marginalização dos homens negros apresentamos as três imagens que seguem abaixo.

\footnotetext{
${ }^{5}$ Esta fantasia entra na lógica da prática teatral BlackFace, na qual atores e atrizes brancos pintam seus rostos de preto para representarem homens e mulheres negros(as), resumindo essas pessoas à cor de sua pele e traços estereotipados.
} 


\section{Figura 6}

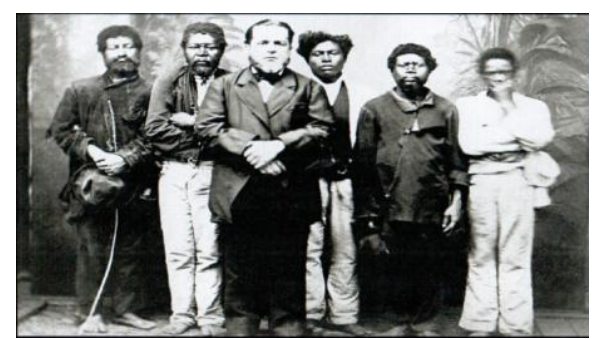

Fonte: Militão Augusto de Azevedo, Senhor com seus escravos. Museu Paulista, USP.

Figura 7

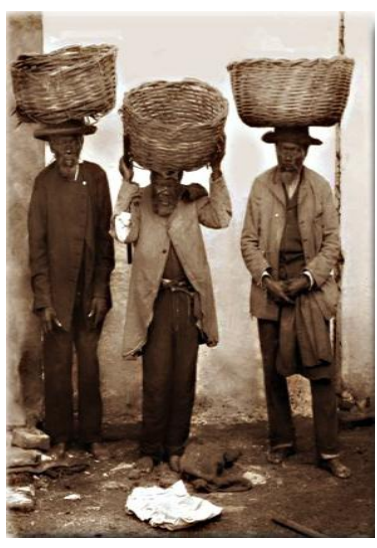

Fonte: Herr Colembusch, Negros libertos em Porto Alegre em 1895. Acervo Ronaldo Bastos.

\section{Figura 8}

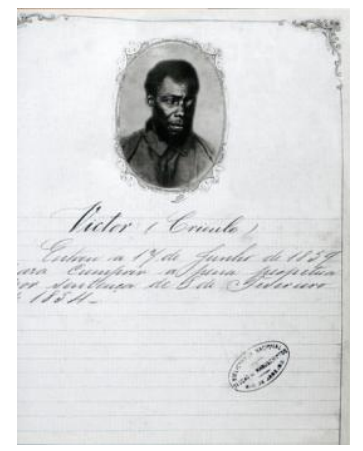

Fonte: Ficha de identificação de prisioneiro da Casa de Correção da Corte. Nela se lê: "Victor (Crioulo) Entrou em 14 de Junho de 1859 para cumprir pena perpétua por sentença de 8 de Fevereiro de 1854".

A primeira das três imagens acima, intitulada Senhor com seus escravos, foi fotografada por Militão Augusto de Azevedo ${ }^{6}$ em data desconhecida, em que pudemos notar o protagonismo do homem branco em detrimento da do homem negro que ocupa uma posição

\footnotetext{
${ }^{6}$ Ver Fig. 6
} 
de inferioridade. A segunda imagem apresenta negros libertos em Porto Alegre, no ano de 1895, no pós-abolição, descalços e em trajes maltrapilhos, abandonados e marginalizados ${ }^{7}$, mesmo após a assinatura da Lei Áurea. Já a terceira trata-se de um documento, a ficha de identificação de um prisioneiro da Casa de Correção da Corte, condenado por agressão ao seu senhor $^{8}$. Diante disso, foi levantada a questão da resistência por parte dos(as) escravos(as), como se deram a criação dos quilombos, espaços de convivência e resistência negras, bem como a representação social desses homens e os reflexos dessa condição social até hoje.

Trouxemos esses cenários à contemporaneidade e destacamos em um mosaico de imagens de diversos contextos, períodos, personagens e espaços, as rupturas e continuidades das representações mostradas anteriormente.

\section{Figura 9}

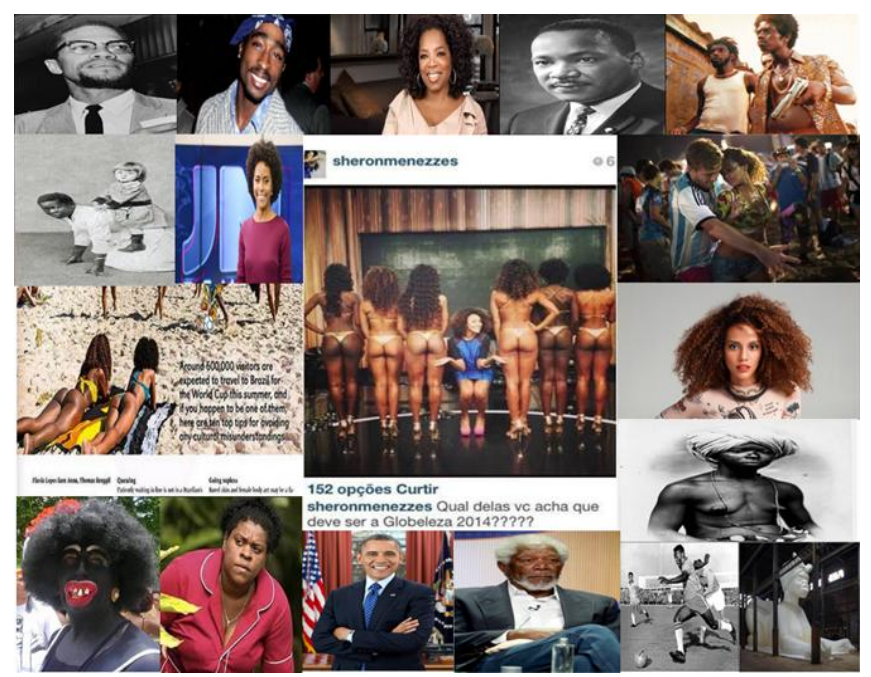

Fonte: Montagem produzida por Thaís Lima.

Esse quadro era composto de fotografias de ícones muito importantes na cultura e luta dos movimentos negros, de mulheres e homens negros que ocupavam e ainda ocupam espaços artísticos e políticos, cenas de filmes e novelas brasileiras que reforçam e ridicularizam a imagem estereotipada das pessoas negras, além de imagens que retratam a objetificação e a hiperssexualização de mulheres negras e de seus corpos, em fotografias que sequer mostram os seus rostos, descaracterizando sua identidade e resumindo-as a uma exposição sexualizada. Mostramos a imagem da capa de uma reportagem ${ }^{9}$ com duas mulheres negras de biquíni na praia cujo título tratava de dez dicas para aproveitar o Brasil, veiculada internacionalmente durante a Copa do Mundo, sediada no Brasil em 2014.

\footnotetext{
7 Ver Fig. 7

${ }^{8}$ Ver Fig. 8

${ }^{9}$ Ver Fig. 10
} 


\section{Figura 10}

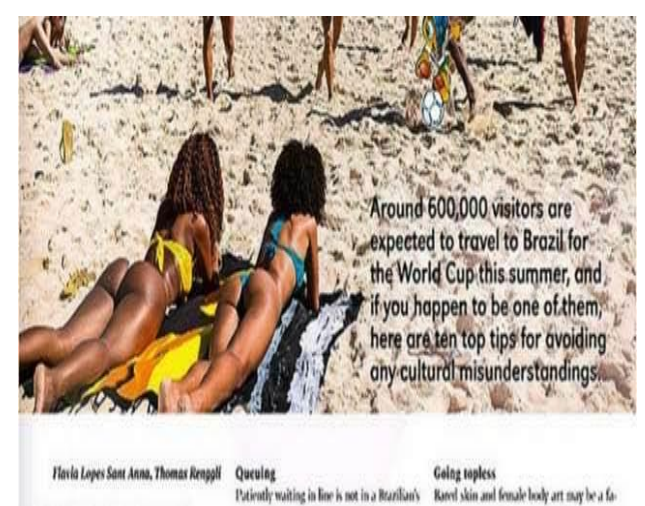

Fonte: Ver matéria sobre a revista em: http://oglobo.globo.com/esportes/copa-2014/cartilha-da-fifa-para-turistasestrangeiros-causa-polemica-11956639.

Em todo o tempo que tivemos para explicar a história dessas imagens, notamos que os estudantes demonstravam bastante interesse, embora estivessem muito tímidos para se pronunciarem, salvo algumas exceções.

Ao encerrarmos a série de exposições iconográficas, contextualizando e historicizando como se deram as construções dessas imagens, sugerimos aos estudantes que formassem grupos e produzissem, de maneira livre, suas impressões acerca do que abordamos em sala de aula. Obtivemos uma variedade de resultados. Dois alunos, inspirados na ficha de identificação de um escravo prisioneiro exposta durante a nossa apresentação, optaram por encenar para a turma um momento de resistência e revolta de um escravo para com o seu senhor. Um grupo de quatro alunos optou por cantar a música Negro Drama ${ }^{10}$, do grupo de rap Racionais MC's. Observamos, com essa apresentação em específico, que eles compreenderam bem o peso histórico implícito nas imagens que expusemos, já que a música abordava a discriminação, o racismo e violências sofridas por pessoas negras. Além dessas apresentações, o restante da turma nos entregou redações, uma poesia e um desenho sobre o que eles apreenderam com a nossa ação pedagógica.

No poema que recebemos, um aluno escreveu em versos o que ele pensa sobre ser negro no Brasil, inspirado no rap apresentado pelos colegas:

Me diga um negro que nunca viveu um drama

Andando na favela, jogando na lama

Me diz um que nunca foi parado na rua

Sem motivo, por um porco fardado

\footnotetext{
${ }^{10}$ Ver a letra da música em: <https://www.letras.com.br/racionais-mcs/negro-drama>
} 
Que diz que preto é bandido

E esse problema ainda demora pra acabar

Pois não falta mídia forjada pra alienar

Fazendo assim a população de massa de manobra

Num país onde negro só é elogiado por jogar bola

E neste mesmo país do carnaval

Você encontra crianças para turismo sexual

Tomara que um dia a gente possa aprender

Que o negro e o pobre são iguais a você.

Já outro aluno escreveu sua opinião sobre o lugar que o negro ocupa na sociedade brasileira. Para ele

o negro sempre foi ridicularizado e desvalorizado diante da sociedade, sempre ocupando cargos mais baixos em que cargo mais altos são apenas exceções. Toda essa hipocrisia se deve ao fato do passado histórico que eles sofreram e que ainda está presente até os dias atuais, em que são quase sempre valorizados apenas pelo seu esforço físico. Essa situação é agarrada pela falta de oportunidade e pela necessidade de irem trabalhar mais cedo, para que possam ajudar suas respectivas famílias. Para que essa situação possa mudar, é necessário que essa visão seja transformada e que nos botemos no lugar do outro.

Sobre o que os estudantes acharam da oficina que aplicamos, um grupo de alunas escreveu:

O que nós vimos hoje na palestra é na verdade um resumo do que vemos no nosso dia a dia. Os negros de antigamente e os de hoje em dia não têm muita diferença, como por exemplo, a questão de escola, trabalho e vida. Foi abordado muito bem esse assunto, pois eles deram exemplos a partir de imagens retiradas de vários meios de comunicação. As mulheres, não somente as negras, mas principalmente elas são vistas de um modo sexual pela sociedade, e a opinião dos professores que apresentaram foi ótima, pois eles mostraram que desde sempre as mulheres foram representadas assim.

Além disso, um dos alunos com grandes inclinações artísticas desenhou um rosto cuja metade correspondia a um homem branco e a outra metade a um homem negro, com a frase "we are one" (nós somos um) escrita embaixo do desenho.

Percebemos, com a nossa oficina que muitos dos estudantes se sentiram tocados com as imagens e históricas que apresentamos em sala de aula. No ato de nossa apresentação, uma das alunas levantou a mão e disse: "minha mãe é negra e funcionária pública, no setor onde ela trabalha, ela é a única negra”. Em uma sala de aula, cuja maioria dos estudantes se identifica como pardos, morenos e negros, nos evidencia a proximidade desses estudantes 
com o conteúdo que nos propusemos a apresentar. Falas como a da aluna citada é um exemplo disso.

Os resultados obtidos em nossa pesquisa-ação foram bastante positivos e revelam as aprendizagens que os estudantes puderam obter nessa prática pedagógica de com objetivos antirracista e antissexista. Seguindo as etapas que compõe esse método de análise e intervenção em sala de aula, pudemos primeiramente identificar certa defasagem no que concerne a aprendizagem desses estudantes sobre alguns aspectos da história e cultura afrobrasileira como, por exemplo, os quilombos e resistências de indivíduos negros escravizados no Brasil. Conseguimos aliar em nossa apresentação, para além das imagens, os fatores que emergiram na construção e fixação daquelas imagens de maneira representacional.

A partir do momento em que tivemos a oportunidade de explicar os motivos que acarretaram no caráter representacional dessas imagens, pudemos desnaturalizar vários dos estereótipos que a televisão, os filmes, os livros didáticos e outros veículos de comunicação nos transmitem. Ao desnaturalizar as representações abrimos espaços para que novas representações possam surgir e, desse modo, valorizar e reconhecer a multiplicidade de práticas, protagonismos e subjetividades assumidas por pessoas negras no Brasil e no mundo. Buscamos historicizar cada uma dessas imagens com os estudantes e, através disso conduzir a uma conscientização e aprendizagem dos efeitos dessas imagens e dos fatores políticos/sociais/econômicos que influenciaram e influenciam diretamente na perpetuação do racismo e sexismo no tempo presente.

\section{Considerações finais}

Quando ligamos nossas televisões e assistimos às novelas ou às propagandas comerciais, deparamo-nos sumariamente com mulheres negras sendo representadas ou em posições de subalternidade ou com seus corpos expostos. Crescemos no invólucro social e midiático que reafirma a discriminação, o racismo e a violência às pessoas negras. O processo de desnaturalização e transformação dessa cultura é também tarefa intrínseca do sistema escolar e educativo, especialmente, do ensino de história.

Historicizar como se deram os processos de construção e cristalização de representações nos permite fazer uma análise acerca do conteúdo representacional de maneira investigativa, a fim de compreendermos que este conteúdo é uma correlação de processos mentais, sociais e culturais, que são partes de uma construção social e, sendo assim, é relevante que tenhamos em vista que estas representações são frutos também de uma 
reapropriação de conteúdos advindos de outros períodos cronológicos (VILLAS BÔAS, ; SOUSA, 2011, p. 216).

Quando entramos em sala de aula, apresentamos uma série de questões relacionadas ao racismo e sexismo, e observamos as reações, dúvidas e reflexões dos estudantes, de certa forma enxergamo-nos neles. Não há, nesse caso, qualquer hierarquização demarcada capaz de evidenciar que detemos maior conhecimento que os estudantes em torno dessas questões. Assim como eles, crescemos assistindo essas formas de representações na televisão, nos filmes e nos livros e acabamos também acreditando serem, estas, a maneira correta e natural desses indivíduos serem representados. Isso é fruto, também, da "colonização do saber" em que a cultura, padrões de beleza e bons referenciais parecem ser sinônimos do ocidente branco, masculino e de descendência européia.

Poder desnaturalizar e desmistificar as representações estereotipadas de gênero/raça no contexto escolar nos remete à afirmação de Nilma Lino Gomes (1996), exposta na introdução deste artigo, quando ela diz que a escola não é um espaço alheio às questões que permeiam nossa realidade sociocultural. É nesse sentido que buscamos trazer para o espaço da escola e do ensino de história tais questões.

Sabemos que a docência é por vezes um árduo ofício, mas quando provocamos nesses estudantes o questionamento sobre a forma como as pessoas negras são representadas e apresentamos a eles os fatores decisivos para a construção e manutenção dessas representações, bem como as consequências delas para esses indivíduos, sentimos que a educação pode ser sim um mecanismo capaz de colaborar na reverter transformação desse quadro marcado por profundas desigualdades, negligências, discriminações e violências que o racismo e o sexismo ainda são capazes de provocar. 


\section{REFERÊNCIAS BIBLIOGRÁFICAS}

BACKZO. Bronislaw. A imaginação social. In: LEACH, E. et al. Anthropos-Homem. Lisboa: Imprensa Nacional: Casa da Moeda, 1985. p. 296-332.

BARROS, José D'Assunção. A Construção Social da Cor - Desigualdade e Diferença na construção e desconstrução do Escravismo Colonial. XII Encontro Regional de História da ANPUH. Rio de Janeiro, 2006. Disponível em: http://encontro2008.rj.anpuh.org/resources/content/anais/1215309488_ARQUIVO_AConstru caoSocialdaCor.revisto.pdf Acesso em: 11 Jun. 2016.

Bilge, Sirma. (2009), “Théorisations féministes de l'intersectionnalité”. Diogène, 1 (225): 70-88

BRAGA, Amanda. Retratos em branco e preto: discursos, corpos e imagens em uma história da beleza negra no Brasil. Tese (Doutorado) - UFPB/CCHLA. João Pessoa, 2013. Disponível em: http://www.cchla.ufpb.br/ppgl/wpcontent/uploads/2013/06/images_AmandaBraga.pdf Acesso em: 11 Jun. 2016.

BRASIL, Ministério da Educação/Secretaria da Educação Continuada, Alfabetização e Diversidade. Orientações e ações para a educação das relações étnico-raciais. Brasília: SECAD, 2006. Disponível em: http://portal.mec.gov.br/dmdocuments/orientacoes_etnicoraciais.pdf Acesso em 09 de mar. 2016.

BRASIL. Lei 11.645, de 10 de marco de 2008. Disponível em: http://www.planalto.gov.br/ccivil_03/_ato2007-2010/2008/lei/111645.htm Acesso em: 15 mai. 2015.

ENGEL, Irineu Guido. Pesquisa-ação. Educar em revista. Curitiba, n. 16, p. 181-191, 2000. Disponível em: http://www.educaremrevista.ufpr.br/arquivos_16/irineu_engel.pdf Acesso em: 18 Jun. 2016.

ERMAKOFF, George. O negro na fotografia brasileira do século XIX. Rio de Janeiro: George Ermakoff Casa Editorial, 2004.

GANDELMAN, Luciana M. "Gênero e ensino: parâmetros curriculares, funcionalismo biológico e teorias feministas". In: ABREU, Martha; SOIHET, Rachel (Org.). Ensino de história: conceitos, temáticas e metodologia. Rio de Janeiro: Casa da Palavra, 2003.

GIACOMINI, Sonia. Mulher e Escrava: Uma introdução histórica ao estudo da mulher negra no Brasil. Rio de Janeiro: Vozes, 1988, p.66.

GUARATO, Rafael. Por uma compreensão do conceito de representação. III Seminário Nacional de História e Historiografia. UFOP, Mariana-MG, 2009. Disponível em: http://www.historiaehistoria.com.br/materia.cfm?tb=artigos\&id=127\#_edn1 Acesso em: 18 Jun. 2016.

GOMES, Nilma Lino. Educação, raça e gênero: relações imersas na alteridade. Cadernos Pagu, vol. 6-7, pp. 67-82,1996. Disponível em: </cadpagu_1996_6.7_5_GOMES.pdf>. Acesso em 05 Abr. 2017. 
HALL, Stuart. Cultura e Representação / Stuart Hall; Organização e Revisão Técnica: Arthur Ituassu; Tradução: Daniel Miranda e William Oliveira. Rio de Janeiro: Ed. PUC-Rio: Apicuri, 2016.

Instituto de Pesquisa e Economia Aplicada. IPEA. "Nota técnica - Estupro no Brasil: uma radiografia segundo os dados da Saúde". Brasília, março de 2014. Disponível em < http://www.ipea.gov.br/portal/images/stories/PDFs/nota_tecnica/140327_notatecnicadiest11.p df $>$. Acesso em 03-02-2017.

JODELET, Denise. Representações sociais: um domínio em expansão. In: JODELET, D. (Org.). As representações sociais. Rio de Janeiro: EdUERJ, 2001.

OLIVA, Anderson R. Entre máscaras e espelhos: reflexões sobre a Identidade e o ensino de História da África nas escolas brasileiras. Revista História Hoje, 1(1), p. 29-44, 2012. (http://www.anpuh.org/revistahistoria/view?ID_REVISTA_HISTORIA=15. Acesso em: 18 Jun. 2016.

LAURETIS, Teresa de. "A Tecnologia do Gênero". In: HOLLANDA, Heloisa Buarque (Org.).Tendências e impasses: o feminismo como crítica da cultura. Rio de Janeiro: Rocco, 1994.

NAVARRO-SWAIN, T.. História feministas, história do possível. In: Cristina Stevens; susane oliveira rodrigues; valeska zanello. (Org.). Estudos feministas: articulações e perspectivas. 1ed.florianópolis: editora mulheres, 2014, v. , p. 613-620.

OLIVEIRA, Susane Rodrigues de. História Indígena: Saberes Discentes, Práticas Escolares e Formação Docente no Distrito Federal. História \& Perspectivas (Online), v. 53, p. 211-238, 2015. Disponível

em: http://www.seer.ufu.br/index.php/historiaperspectivas/article/view/32773/17716 Acesso em 11 Jun. 2016.

PAVIANI, Neires M. S.; FONTANA, Niura M. Oficinas pedagógicas: relato de uma experiência. In: Conjectura, Caxias do Sul, v. 14, n. 2, p. 77-88, maio/ago. 2009.

PEREIRA, Bergman de Paula. De escravas a empregadas domésticas - A dimensão social e o "lugar" das mulheres. Disponível em: http://www.snh2011.anpuh.org/resources/anais/14/1308183602_ARQUIVO_ArtigoANPUHBergman.pdf Acesso em: 11 Jun. 2016.

RAGO, Margareth. O corpo exótico, espetáculo da diferença. Labrys Estudos Feministas, 2008. Disponível em: http://www.labrys.net.br/labrys13/perspectivas/marga.htm Acesso em: 11 Jun. 2016.

REVISTA FÓRUM. Marginalização do negro é fruto da abolição inconclusa. Disponível em: http://www.revistaforum.com.br/digital/147/marginalizacao-negro-e-fruto-da-abolicaoinconclusa/ Acesso em: 18 Jun. 2016.

Revista FAPESP: A África nos genes do povo brasileiro. Abril 2007, Edição 134, p. 2 -3.

ROUQUETTE, M.-L. Sur la connaissance des masses: Essai de psychologie politique. Grenoble: Presses Universitaires de Grenoble, 1994.

SHOHAT, Ella; STAM, Robert. Crítica da Imagem Eurocêntrica. Tradução: Marcos Soares. São Paulo: Cosac Naify, 2006.

SOUZA, Rolf Ribeiro de. As representações do homem negro e suas consequências. Texto publicado na Revista Fórum Identidades. Ano 3, Volume 6, em jul-dez de 2009, da UFSE. Disponível

em: 
http://200.17.141.110/periodicos/revista_forum_identidades/revistas/ARQ_FORUM_IND_6/ DOSSIE_FORUM6_07.pdf Acesso em: 14 de jun. 2016.

THIOLLENT, Michel. Metodologia da Pesquisa-Ação. São Paulo: Cortez, 1985.

MALDONADO-TORRES, Nelson. Sobre la colonialidad del ser, contribuciones al desarrollo de un concepto. In: 626 DO COLONIALISMO À COLONIALIDADE ... CADERNO CRH, Salvador, v. 27, n. 72, p. 613-627, Set./Dez. 2014 CASTRO-GOMEZ, Santiago; GOSFROGUEL, Ramón (Comp). El giro decolonial: reflexiones para una diversidad epistémica más allá del capitalismo global. Bogotá: Universidad Javeriana-Instituto Pensar, Universidad Central-IESCO, Siglo del Hombre, 2007. P. 127-167.

WAISELFISZ, Julio Jacob. Mapa da Violência 2015 - Homicídio de Mulheres no Brasil. $1^{\text {a }}$ Ed. Brasília-DF. 2015. Flacso - Faculdade Latino-Americana de Ciências Sociais. p. 11. 